\title{
25 Research Square \\ Design the Model of Sport Development in Military Hygiene and Cure Branch Staff
}

\section{Hosein Shirvani}

Exercise Physiology Research Center, Life Style Institute, Baqiyatallah University of Medical Sciences, Tehran, Iran

\section{Mohammad Karim Bahadori}

Health Management Research Center, Baqiyatallah University of Medical Sciences, Tehran, Iran

Abolfazl Darvishi ( $\sim$ abolfazl446@yahoo.com )

Exercise Physiology Research Center, Life Style Institute, Baqiyatallah University of Medical Sciences, Tehran, Iran https://orcid.org/0000-0002-2753-2416

\section{Research}

Keywords: Management, Individual, Military, Environmental, Participant Sport, Amos

Posted Date: September 25th, 2020

DOI: https://doi.org/10.21203/rs.3.rs-78836/v1

License: (1) (1) This work is licensed under a Creative Commons Attribution 4.0 International License. Read Full License 


\section{Abstract}

Background: Sport, as a phenomenon in many people's lives in society helps improve their health and well-being, which is very important for any society's development. Promoting physical activity is one of the most important and effective strategies to reduce the risk of diseases, reduce social deviations and increase the vitality of communities.

Methods: The present study was conducted in a mixed method. The statistical population of the study included faculty members and physical education professors of the Military universities, managers, coaches and athletes in the field of military. In the qualitative stage, the factors were identified through interviews with 11 people; in the quantitative stage, to collect the data was used a researcher-made questionnaire obtained from the interview and study of research background. The validity of the questionnaire was assessed by calculating the indicators of Content Validity Ratio and content validity index and for calculate the reliability was used to cornebach's alpha. For data analysis was used of structural equation modeling in format of SPSS20 and AMOS23 software.

Results: The results of modeling structural equations showed that the dimensions of management, environment and infrastructure had a positive and significant relationship with the dimension of sport participation and individual dimension was not significant relationship with sport participation.

Trial registration: Not applicable

Conclusion: The results of this research can be used to make more progress in the sports of the Armed Forces personnel and ultimately increase the morale and health of these people.

\section{Introduction}

Human resources is an important structures in a variety of fields spanning from micro scholarship in psychology to macro scholarship in economics (1). Human resources are people who work for companies and organizations and the part that is responsible for managing employees in them. It is the work force of any organization. According to Gunnigle et al (1997), people are the life blood of organization. an organization's workforce represents one of its most assets and capital consequently, the amount of attention paid to the workforce effectively is a critical element in improving and sustaining organization performance. Managing people is one of the most difficult aspects of organization management. It means dealing with people who differ physically and psychologically (2). In today's world, what matters most is manpower and even the greatest economists believe that it is manpower that ultimately creates the process of economic and social development of a society and all the efforts of organizations and departments are to make sure that the human resources they want are present in their work environment with good motivation and satisfaction. One of the most important ways to gain such workforce is to engage in physical activity and sport. 
The real development and progress of countries has different indicators that one of the most important of which is sport (3) and for decades, the role of sport in society has been the focus of researchers and scholars (4). Sport and sport activities are part of the culture of any nation (5). Numerous studies have concluded that exercise and related activities have a positive effect on people's Hygiene and well-being (6-7) and it is essential for any society to develop it. Sport is a reflection of today's society. Through the promotion of sport, sport activities are a tool for the development of societies and peace in different cultures (8). Sport has existed since the beginning of life and is used to achieve various goals. According to Obiyemi and Musa (2003), sports are the activities for the enjoyment and satisfaction of personal gain and involving powers, skills, competition and strategy engaged in. Traditionally, the enjoyment and satisfaction of personal gain were the main aim of participating in sports (9). Sport is currently influential in world politics; therefore, efforts should be made to encourage people to participate in sports. Globally, sports is considered as the creator of beauty and a means to ethical values that brings about peace, unity and understanding among people of all races, during sports participation which wholly the result of social invention and social heritage (9). Sport development as a public policy priority has historically been on the periphery of governments' political agendas. This is not the case in the early twenty-first century however and in the last decade in many countries public policies for sport development-related activity have increased in salience (10). Ensuring concerted efforts to position sport as a means for development in society are successful requires sophisticated endeavors by researchers and practitioners to understand effective processes and measurable outcomes of these sport programs (11). As a social event, sport brings people together in pursuit of physical, mental, social and political progress (9). With the significant increase in the role of sport in economic, social, cultural and even political development, progress in the field of sport has become one of the strategic priorities of planners in different countries of the world. Therefore, it is necessary to pay attention to the development of sport in every country.

Promoting physical activity is one of the most important and effective strategies to reduce the risk of some diseases, reduce social deviations, and increase the vitality of communities. In fact, sport as important part of education has a fundamental position and a clearing, and its various functions are evident in society (12(. Sotiriadou et al (2008) believe that, it is necessary to pay attention to many dimensions in the development of sport. At the macro and micro levels, many factors affect the spread and promotion of sport; they also have defined sport development as a process in which are created at that effective opportunities, processes, systems, and structures so that people in all specific groups and groups can participate in sport and recreation and improve their performance (13). One of the organizations that play an important role in the development and expansion of sport in the Islamic Republic of Iran is the armed and military forces, and it is very important to pay attention to them.

The capability of the military and military is very important and it is necessary to pay attention to it, because the military are the guardians of the independence, security, and territorial integrity of the country; therefore, it is very important to pay attention to the issues that cause optimal performance in the military and they should pay more attention to the readiness and Hygiene of their employees than other organization (14); One of the social institutions whose authority and power affect the progress and development of other social institutions directly and indirectly is the military. Undertaking physical activity 
plays an important role in the battle against the ever-increasing problems - seen both within a society and its military - of being overweight, obesity, circulatory system diseases, and diabetes (15-17). One of the elements of the success of the military in carrying out the assigned missions is having physical fitness and having the necessary capabilities to use the body in different situations and one of the reasons for the development and expansion of sport and physical training from the distant past has been the need to increase the readiness of the military and now, scientific, practical and physical development of the Military, which is directly related to the combat capability of these forces is one of the necessities of the military physical education (18). Sport and physical activity is one of the most important and influential parts for the people who connect their lives with the military system. That the quality of work and the performance of the duties of these forces depends on the fitness level and physical preparedness (19). One of the key pillars of the success of the military is its staff; On the other hand, the Hygiene and Cure Military Branch Staff are responsible for providing Hygiene and wellness services to the country's Military and paying attention to sport as one of the ways to prevent diseases and improve Hygiene can be effective in the tendency of other employees and forces to sport.

Research has shown that physical activity and exercise are one of the things that can reduce stress and increase the efficiency of police forces (20-21). Also some studies have shown the effect of individual factors on the development of exercise and the development of sports participation (22-23). Hu et al. (2018) stated that some of the factors in the development of Taiwan's professional volleyball include improving the quality of media coverage, improving competition and athlete's standards, holding international events, holding competitions for professional teams, supporting basic teams, creating the right reward system for players and coaches, creating a suitable system for training coaches and providing the necessary facilities and equipment (24). Krsmanović et al. (2014) cited human resources as one of the main and influential sources in the development of sport, which include volunteers, teachers, coaches, leaders and managers (25). Wang (2013) concluded that lake factors such as scientific progress, support, coordination and communication between different sectors, creating equal opportunities, financial support, Specialists in the required number and facilities has led to the lack of development of sport for all in China (26). In his paper, De Bosscher et al. (2006) stated that some factors influencing international success in sports include financial support, talent identification and talent development, educational facilities and scientific research (27); Zarei et al. (2017) presented strategies for the development of university sport, including the development of teaching sport-related sciences, the development of championship sport, the construction of sport facilities, comprehensive planning for university sport, and the development of programs to attract women to sport, Expanding the relationship between university administrators and sport and improving the quality of equipment (28). Ajadi et al. (2017) in their study for development of sport in Nigeria's military forces pointed to factors such as providing advanced sport equipment, improving the maintenance of sport facilities, easy access to sport facilities, providing the required and qualified manpower for sport such as the coach, coordination between the manpower involved in sport, encouraging participants by coaches, providing the budget and financial resources needed for sport, and managing the budget allocated to sport (9). Wang and Lu (2017) also stated that factors in the development of sport in universities include increasing the number 
of participants, increasing students' awareness, the existence of sport equipment in universities and colleges, organizing sport camps, conducting major sporting events and conducting related research (29).

Despite the emphasis on the exercise of the Military in the country's major sport programs, it is not clear to what extent has been used the predicted capacities in this program to develop sport in the Military staff section; also, yet research has been not done about the development of sport for the Military Hygiene and Cure Branch Staff; Therefore, identifying the factors, items, and dimensions of sport development in the Hygienecare sector of the Military Hygiene and Cure Branch Staff will help to provide effective planning for the development of sport in this branch. In addition, it created a new framework in this area and introduced practical strategies to correction, improvement and upgrade the level of development of sport for the staff of the military in the Hygiene and cure military branch. It is expected that process of growth and development of sport in this branch should be facilitated using the identified factors and prepare preparations for the development of sport in the military; Also, the Hygienecare branch is one of the sectors that is directly related to the Hygiene of the military and since sport is one of the most effective ways to increase people's Hygiene, and this category also works for the Hygiene of employees, so at first they should to pay attention to sport and their development to be able generalize to other employees of the military; so according to said cases, conducting this research can be an effective step in promoting sport in the military Hygiene and cure branch. Therefore, in order to complete previous research in the field of military sport and measuring the factors influencing the development of sport for the Military Hygiene and Cure Branch Staff, the researcher intends to design the model of sport development of Military Hygiene and Cure Branch Staff.

\section{Method}

The present study conducted with descriptive - analytical which is done by Mixed Method and in the form of consecutive exploration.

\section{Participants}

The statistical population of the study included faculty members and physical education professors of the Military universities, managers, coaches and athletes in the field of military. In the qualitative phase was performed interview with 11 peopleand stopped after reaching theoretical saturation. The sample method was targeted and snowball in the qualitative stage. In the quantitative phase sampling method was simple random that based on the number of needed samples to model structural equations in which 250 people were selected as statistical samples and the questionnaire was distributed among them and 236 questionnaires were completed and returned.

\section{Data Collection}


In the qualitative stage, a semi-structured interview was used to identify the factors in the sport development of Military Hygiene and Cure Branch Staff. The research instrument in quantitative stage was a researcher-made questionnaire from the Likert spectrum obtained from the interview and study of research background and related studies which includes 5 dimensions, individual (questions 1 to 3 ), environmental (cultural and social component including questions 4 to 8 , economic component including questions 9 and 10, political and legal component including questions 11 to 13); infrastructure dimension (technology component including questions 14) And 15, component of facilities and equipment including questions 16 to 24) dimension of management (financial resources component including questions 15 to 28 , component of human resources including questions 28 to 32, planning component including questions 33 to 35) and Sport participation development (educational sport component And training includes questions 36 and 37, the component of public and recreational sport, including questions 38 and 39 , and the component of competitive and championship sport, including questions 40 to 43). To determine the validity of the questionnaire were used the opinions of sport management professors and Content Validity Ratio and Content Validity Index; also, the reliability of the questionnaire was also assessed through Cronbach's alpha $(a=0.86)$.

\section{Data Analysis}

In the qualitative stage, after conducting and editing the interviews were coded and classified the different opinions in the same conceptual groups and analyzed qualitatively. In the qualitative stage for describe the data were used descriptive statistics. For inferential data analysis were used Cronbach's alpha and to determine the relationships between the variables in the form of a model was used structural equation modeling (SEM). To do above tests were used SPSS20 and AMOS23 statistical software.

\section{Results}

In this section, the findings are presented in two descriptive and inferential sections.

As can be seen in Table 1, the largest number of people in the statistical sample were male, athlete, in the age group of 36 to 45 years, in the field of physical education, had a bachelor's degree and had a background of 1 to 5 years. 
Table 1.

Demographic information of the respondents of the questionnaire

\begin{tabular}{|c|c|c|}
\hline \multirow[t]{2}{*}{ Baseline characteristic } & \multirow[b]{2}{*}{$\mathrm{n}$} & \multirow[b]{2}{*}{$\%$} \\
\hline & & \\
\hline \multicolumn{3}{|l|}{ Gender } \\
\hline man & 233 & 94.5 \\
\hline woman & 13 & 5.5 \\
\hline \multicolumn{3}{|l|}{ Occupation } \\
\hline management & 38 & 16.1 \\
\hline professor & 22 & 9.3 \\
\hline Athlete & 114 & 48.3 \\
\hline coach & 62 & 26.3 \\
\hline \multicolumn{3}{|l|}{ Age } \\
\hline 25 years and younger & 62 & 26.3 \\
\hline $26-35$ years & 71 & 30.1 \\
\hline $36-45$ years & 85 & 36.0 \\
\hline $46-55$ years & 17 & 7.2 \\
\hline 56 years and older & 1 & 0.4 \\
\hline \multicolumn{3}{|l|}{ Field of Study } \\
\hline Physical Education & 135 & 57.2 \\
\hline Others & 101 & 42.8 \\
\hline \multicolumn{3}{|l|}{ Degree of education } \\
\hline Associate's degree and lower & 43 & 18.2 \\
\hline Bachelor's degree & 120 & 50.8 \\
\hline Master's Degree & 59 & 25.0 \\
\hline \multicolumn{3}{|l|}{ PhD } \\
\hline Background & 14 & 5.9 \\
\hline $1-5$ years & 145 & 61.4 \\
\hline $6-10$ years & 59 & 25.0 \\
\hline
\end{tabular}




\begin{tabular}{|lll|}
\hline Baseline characteristic & \multicolumn{2}{|}{} \\
\cline { 2 - 3 } & $\mathbf{n}$ & $\mathbf{\%}$ \\
\hline $11-15$ years & 22 & 9.3 \\
\hline $16-20$ years & 6 & 2.5 \\
\hline 20 years and older & 4 & 1.7 \\
\hline
\end{tabular}

As can be seen in Table 2, after examining the background of the research and conducting interviews, 55 factors were identified for the development of sport in Military Hygiene and Cure Branch Staff. 
Table 2.

Extracted Factors

\begin{tabular}{|c|c|c|}
\hline Dimension & Component & Factor \\
\hline \multirow[t]{5}{*}{ Individual } & \multirow[t]{3}{*}{ Demographic } & 1. Age characteristics of staff \\
\hline & & 2. Gender characteristics of staff \\
\hline & & 3. Income level and well-being of staff \\
\hline & \multirow[t]{2}{*}{ Psychology } & 4. Body perception of staff \\
\hline & & $\begin{array}{l}\text { 5. Staff mental states (such as motivation, self-confidence, } \\
\text { perseverance,...) }\end{array}$ \\
\hline \multirow[t]{13}{*}{ Environmental } & \multirow{7}{*}{$\begin{array}{l}\text { cultural and } \\
\text { social }\end{array}$} & 6. Implement cultural programs to institutionalize sport \\
\hline & & 7. Valuation of sport among the staff \\
\hline & & $\begin{array}{l}\text { 8. Development of media and advertising for sport and its } \\
\text { programs }\end{array}$ \\
\hline & & $\begin{array}{l}\text { 9. The attention of the world's media to the sport of the Military } \\
\text { staff }\end{array}$ \\
\hline & & $\begin{array}{l}\text { 10. Membership in social, recreational and sport groups and } \\
\text { networks }\end{array}$ \\
\hline & & 11. Social security for sport activities \\
\hline & & 12. Institutionalization of sport in families \\
\hline & \multirow[t]{3}{*}{ Economical } & 13. Expenditure on sport in the household shopping cart \\
\hline & & 14. The economic situation of the country \\
\hline & & 15. Invest in staff sport \\
\hline & \multirow[t]{3}{*}{$\begin{array}{l}\text { Political and } \\
\text { legal }\end{array}$} & $\begin{array}{l}\text { 16. Existence of organizational and executive rules and } \\
\text { regulations in the sport of the Military }\end{array}$ \\
\hline & & $\begin{array}{l}\text { 17. Following the exercise of staff from the policies of } \\
\text { international organizations }\end{array}$ \\
\hline & & $\begin{array}{l}\text { 18. Existence of developmental documents in sport (educational, } \\
\text { public, competitive and championship) }\end{array}$ \\
\hline Dimension & Component & Factor \\
\hline \multirow[t]{3}{*}{ Infrastructure } & \multirow[t]{3}{*}{ Technology } & $\begin{array}{l}\text { 19. Educational assistance technology in the development of } \\
\text { sport for the staff of the Military }\end{array}$ \\
\hline & & $\begin{array}{l}\text { 20. The use of information technology (IT) in the sport } \\
\text { management of the military }\end{array}$ \\
\hline & & 21. Learn more about sport through communication technology \\
\hline
\end{tabular}




\begin{tabular}{|c|c|c|}
\hline Dimension & Component & Factor \\
\hline & \multirow{9}{*}{$\begin{array}{l}\text { Facilities and } \\
\text { equipment }\end{array}$} & 22. Increase outdoor and indoor sport facilities \\
\hline & & 23. Pay attention to the safety and Hygiene of sport infrastructure \\
\hline & & 24. Ability to access sport facilities and spaces \\
\hline & & $\begin{array}{l}\text { 25. Proportion of distribution of sport facilities and spaces based } \\
\text { on the number of staff }\end{array}$ \\
\hline & & $\begin{array}{l}\text { 26. Standard system of equipment and facilities sport for the } \\
\text { Military staff }\end{array}$ \\
\hline & & 27. Creating sport places in different provinces and cities \\
\hline & & 28. Existence of special places and spaces for men and women \\
\hline & & 29. Specialized and standard equipment in various sports \\
\hline & & 30. Safety of sport equipment \\
\hline \multirow[t]{8}{*}{ Management } & \multirow{4}{*}{$\begin{array}{l}\text { Financial } \\
\text { resources }\end{array}$} & 31. Allocate sufficient funds for staff sport \\
\hline & & 32. Pay attention and apply revenue generation and marketing \\
\hline & & 33. Standard system of financial resources for military staff sport \\
\hline & & 34. Private investment in military staff sport \\
\hline & \multirow{4}{*}{$\begin{array}{l}\text { Human } \\
\text { resources }\end{array}$} & 35. Giving social status to sport coaches in the military \\
\hline & & $\begin{array}{l}\text { 36. Existence of experienced managers and staffs in the sport of } \\
\text { the military staff }\end{array}$ \\
\hline & & 37. Standard system of human resources for military staff sport \\
\hline & & 38. Active presence of commanders alongside staff for sport \\
\hline
\end{tabular}




\begin{tabular}{|c|c|c|}
\hline Dimension & Component & Factor \\
\hline & \multirow[t]{2}{*}{ Human resources } & $\begin{array}{l}\text { 39. Establish a mechanism for timely punishment and } \\
\text { encouragement }\end{array}$ \\
\hline & & $\begin{array}{l}\text { 40. Use knowledgeable and experienced coaches in staff } \\
\text { sport }\end{array}$ \\
\hline & \multirow[t]{3}{*}{ Planning } & $\begin{array}{l}\text { 41. Set specific goals to improve the position of staff } \\
\text { sport in the military }\end{array}$ \\
\hline & & $\begin{array}{l}\text { 42. Planning (long-term, short-term and operational) to } \\
\text { improve the position of staff sport in the military }\end{array}$ \\
\hline & & $\begin{array}{l}\text { 43. Unity of policy making and elaboration of clear job } \\
\text { descriptions in staffs sport }\end{array}$ \\
\hline & \multirow[t]{2}{*}{$\begin{array}{l}\text { Scientific and } \\
\text { research }\end{array}$} & $\begin{array}{l}\text { 44. Needs assessment and technical research to develop } \\
\text { sport for Hygiene and cure branch staff }\end{array}$ \\
\hline & & $\begin{array}{l}\text { 45. Holding scientific and research seminars in the field of } \\
\text { sport }\end{array}$ \\
\hline \multirow{10}{*}{$\begin{array}{l}\text { Sport } \\
\text { participation } \\
\text { development }\end{array}$} & \multirow[t]{2}{*}{ Educational sport } & 46. Holding educational classes in various sports \\
\hline & & 47. Holding coaching and refereeing classes \\
\hline & \multirow[t]{4}{*}{ Sport for all } & $\begin{array}{l}\text { 48. Holding a national olympiad for public and } \\
\text { recreational sport in this branch }\end{array}$ \\
\hline & & 49. Holding sport for all festivals within the branch \\
\hline & & $\begin{array}{l}\text { 50. Implement inter-branch competitions sport programs } \\
\text { in sport for all }\end{array}$ \\
\hline & & 51. Implementation happy and fun sport programs \\
\hline & \multirow{4}{*}{$\begin{array}{l}\text { Competitive and } \\
\text { championship } \\
\text { sport }\end{array}$} & 52. Holding regional competitions (regions) \\
\hline & & $\begin{array}{l}\text { 53. Holding inter-branch competitions in championship } \\
\text { sport }\end{array}$ \\
\hline & & $\begin{array}{l}\text { 54. Holding national sport competitions for the staff of } \\
\text { the military branches }\end{array}$ \\
\hline & & 55. Employee participation in international competitions \\
\hline
\end{tabular}

The results of the validity study are shown in Table 3 through two indicators of content validity ratio and content validity index. Accordingly, 12 items were removed from the final questionnaire that presented in this table. 
Table 3.

Results of CVI and CVR indicators

\begin{tabular}{|lcc|}
\hline Factor & CVI & CVR \\
\hline Age characteristics of employees & 0.67 & 0.0 \\
\hline Gender characteristics of employees & 0.67 & -0.17 \\
\hline Valuing of sport among employees & 0.67 & 0.33 \\
\hline Expenditure on sport in the household shopping cart & 0.33 \\
\hline The world's media pays attention to the sport of the military staff & -0.33 \\
\hline Establish a mechanism for timely punishment and encouragement & 0.33 \\
\hline Educational assistance technology in the development of sport for the staff of the & 0.16 \\
\hline military & -0.42 & 0.33 \\
\hline Private investment in the sport of the military & 0.5 \\
\hline Needs assessment and technical research to develop sport for Hygienecare staff & & 0.33 \\
\hline Holding scientific and research seminars in the field of sport & 0.33 & 0 \\
\hline Holding public sport festivals within the branch & 0.5 & -0.16 \\
\hline Implementation happy and fun sport programs & & \\
\hline
\end{tabular}

According to Table 4, the fit indices of the final research model show that the final model has a very good fit for the variables of the present study. In other words, they confirm the fit of the model.

Table 4.

Indicators of structural model fit

\begin{tabular}{|llllllll|}
\hline Indicators & CMIN/DF & GFI & AGFI & NFI & IFI & CFI & RMSEA \\
\hline Value & 1.955 & 0.927 & 0.915 & 0.875 & 0.935 & 0.933 & 0.064 \\
\hline
\end{tabular}

The results of Table 5 show that the individual dimension has no significant relationship with the dimensions of research; also, the infrastructure dimension has a positive and significant relationship with environmental, management and sport participation development dimensions; Another result is a positive and significant relationship between management dimension with sport participation development and environmental dimensions; Also, the environmental dimension had a positive and significant relationship with the sport participation development dimension. 
Table 5.

Output results of structural equation model

\begin{tabular}{|c|c|c|c|c|c|c|c|}
\hline Variable & & Variable & Estimate & S.E. & C.R. & $\mathbf{P}$ & $\begin{array}{l}\text { Regression } \\
\text { weight }\end{array}$ \\
\hline Infrastructure & - & Environmental & 0.719 & 0.085 & 8.437 & $\star \star \star \star$ & 0.853 \\
\hline Individual & - & Environmental & 1.728 & 0.697 & 2.480 & 0.013 & 2.569 \\
\hline Individual & $\overline{-}$ & Infrastructure & -1.233 & 0.817 & -1.508 & 0.131 & 0.682 \\
\hline Management & - & Environmental & 0.129 & 0.461 & 7.281 & $\star \star \star$ & 0.111 \\
\hline Management & - & Infrastructure & 1.393 & 0.478 & 2.912 & $\star \star \star \star$ & 1.003 \\
\hline Management & $\overline{-}$ & Individual & -0.407 & 0.346 & -1.176 & 0.240 & -0.234 \\
\hline $\begin{array}{l}\text { Sport participation } \\
\text { Development }\end{array}$ & $\overline{-}$ & Management & 0.352 & 0.601 & 8.586 & $\star \star \star$ & 0.408 \\
\hline $\begin{array}{l}\text { Sport participation } \\
\text { Development }\end{array}$ & $\overline{-}$ & Environmental & 1.001 & 0.255 & 6.147 & $\star * *$ & 0.037 \\
\hline $\begin{array}{l}\text { Sport participation } \\
\text { Development }\end{array}$ & $\overline{-}$ & Infrastructure & 0.531 & 1.022 & 6.520 & $\star \star \star$ & 0.443 \\
\hline $\begin{array}{l}\text { Sport participation } \\
\text { Development }\end{array}$ & - & Individual & -0.008 & 0.335 & -0.024 & 0.981 & -0.005 \\
\hline
\end{tabular}

Based on the structural equation model in Fig. 1, the infrastructure dimension is effective on sport participation development with a coefficient of 0.44 . The environmental dimension with coefficients of $0.11,0.85$ and 0.44 effects on the management, infrastructure and of sport participation dimension, respectively. Also, the infrastructure dimension is effective on management dimension with a coefficient of 1.00 and management dimension is effective on sport participation development with a coefficient of 0.41 . Also, the individual dimension did not have a positive and significant relationship with research dimensions.

\section{Discussion}

Promoting the sport of the military can develop sport culture and increase combat readiness in the country's military and this can be useful in increasing the morale of the country's military and their greater readiness to defend the country's borders and environment. The purpose of the present study was to identify and ranking the sport development factors of Military Hygiene and Cure Branch Staff and the 
results showed that the dimension of sport participation development has the highest rank among the influential dimensions; Also, the results of modeling structural equations showed that the dimensions of management, environment and infrastructure had a positive and significant relationship with the dimension of sport participation development and individual dimension had not a significant relationship with sport participation development.

The results showed that individual dimension did not have a significant effect on the sport participation development which was inconsistent with the results of the research of Rowe et al. (2013) (22) and Geel and Deeter (1988) (23) the reason for this inconsistent may be the difference in the statistical population of the research.

The results of the research show that the environmental dimension has a positive and significant effect on the sport participation development of the military Hygiene and cure branch staff that among its components, the cultural and social factor has the most effect with the effect coefficient of 0.70 and this component includes 5 items of cultural programs for institutionalizing sport, media development and advertising for sport and its programs, institutionalization of sport in families, social security for sport activities and membership in entertainment and sport social groups and networks. The cultural and social environment is one of the main components within the environment it can be used to influence the institutionalization of any subject and through that environment, the desired approach can be expanded among different people; for this reason, from this environment can be used to develop sport in society and made the necessary plans. In military Hygiene and cure branch staff sport, it seems that the effect of the cultural and social environment is more tangible due to its specialization and the priority of factors can be largely explained. One of the requirements for the development of sport in any part of society is to institutionalize the culture of sport among them that the staff of the military are no exception from this rule and it should be done in such a way that sport becomes one of the daily necessities of life of these people; Perform appropriate advertising through various media, implement cultural programs in the field of sport and adopt policy-making in cultural activities in the field of sport can be an effective step in this direction; According to this point that one of the strengths of physical education of the military is the observance of religious and moral standards at all levels and national and international arenas, planning to produce and publish books, bulletins and brochures to promote genuine Islamic and national culture to exploit the sport of military can be one of the effective ways to create Culturalization and development of Islamic and national culture and values which is one of the central goals and values of the military among the military and their families; Therefore, Culturalization and promoting sport among the military Hygiene and cure branch staff is one of the effective factors in the development of sport in this branch.

The results of the research show that the infrastructure dimension has a positive and significant effect on the sport participation development of the military Hygiene and cure branch staff that among its components, the facilities and equipment factor has the most effect with the effect coefficient of 0.78 and this component includes 9 items of increase outdoor and indoor sport facilities, pay attention to the safety and Hygiene of sport infrastructure, ability to access sport facilities and spaces, proportion of distribution of sport facilities and spaces based on the number of staff, standard system of equipment 
and facilities sport for the Military staff, creating sport places in different provinces and cities, existence of special places and spaces for men and women, specialized and standard equipment in various sport and safety of sport equipment which was consistent with the results of Zarei et al. (2017) (28), Ajadi et al. (2017) (9), Wang and Lu (2017) (29) and Wang (2013) (26); This shows that the services provided by the sport system in the community are highly dependent on infrastructure and its development is essential for the greater participation of the military Hygiene and cure branch staff in sport. Since sport facilities and equipments are the most tangible services of the sport institution to individuals, so their priority can be largely justified over the resources and achievements of participation; In fact, one of the requirements for the development of sport in any organization is the development of sport equipment and facilities and its appropriate distribution according to the territorial planning and needs of each region and all sport construction and equipment must be in line with the latest scientific findings. The factor of facilities and equipment is one of the factors that have a positive effect on the development of sport in all sectors, including the sport of military Hygiene and cure branch staff. Many sport cannot be done without its own facilities and equipment, which is many people who are interested in these sport are not able to do it; That's why their presence is necessary for the development of sport; The staff of the military Hygiene and cure branch is no exception and to develop their sport, it is necessary to provide facilities and equipment based on the needs of different sectors; one of the things that needs attention, if possible, separate places can be created for women so that they too can participate more in the sport of the military.

The results of the research show that the management dimension has a positive and significant effect on the sport participation development of the military Hygiene and cure branch staff that among its components, the human resources factor has the most effect with the effect coefficient of 0.84 and this component includes 5 items of giving social status to sport coaches in the military, Existence of experienced managers and staffs in the sport of the Military staff, standard System of Human Resources for Military Staff Sport, active presence of commanders alongside staff for sport and Use knowledgeable and experienced coaches in staff sport which was consistent with the results of Ajadi et al. (2017) (9) and Krsmanović et al. (2014) (25). Today, the role and importance of human resources is considered as one of the most important factors in the process of education and service delivery in human societies. Looking at the stages of human civilization, it becomes clear that the role of manpower has evolved from simple labor to human capital; because progress is inefficient without manpower developments. With its skills and techniques, manpower creates value, attractiveness and desirability for the general public and interested people. In recent decades, human resources have been considered as a smart element; an element that with its skill and creativity plays a key role in the system. Efficient manpower in a country is one of the valuable assets of that country and basically knowledge capital is much more important than production capital. Developing countries benefit from human capital more than physical capital. One of the most important factors in the development of sport is the factor of manpower specialized in this field and given the current situation, it seems that managers can pay more attention to this issue. Expertise and appropriate human resources are one of the important factors for the successful implementation of any program; In this regard, the physical education of the military can be more successful by establishing effective interaction with national and international sport and educational organizations, writing a 
detailed job description of the physical education staff and the conditions for obtaining them; It can also lead to the development of human resources and secondly, to the development of sport in the military by comprehensively training the human resources required in any sport department of the Military, attracting and employing specialized personnel in sport, Also, by holding courses to improve the level of scientific and technical knowledge of trainers on a monthly and annual basis (using internal and external instructors). Because the driving force of any organization is its human resources and the military and its sport are no different, therefore, in order to develop the sport of Military Hygiene and Cure Branch Staff must be attention to this important resource and to promote staff sport is necessary to employ coaches, professional managers and professional athletes in the sport of the Military.

In the field of sport participation development, the dimensions of championship, educational sport and sport for all development were prioritized with coefficients of $0.75,0.77$ and 0.64 , respectively. As mentioned in the hierarchical model of sport, after passing educational sport and sport for all, championship and professional sport are at the top of the pyramid. The development of educational sport and sport for all is the foundation for the development of championship and professional sport; According to the results obtained, it seems that the staff of the military Hygiene and cure branch is more interested in championship sport; Of course, all types of sports must be considered at the same time in order to identify the top talents for championship and professional sport from educational sport and sport for all. Records show that the most popular form of sport in societies is championship. At this level of sport is the emphasis on competition and victory that in fact, these are motivations for people to participate in sport; also in the sport of the military Hygiene and cure branch staff should be considered to championship sport to increase people's motivation to participate in all kinds of sport and increase participation; Therefore, the military in general and the Hygienecare sector in particular can near the educational sport and sport for all also pay attention to championship sport and make staffs more inclined to sport.

Based on the final structural model, the dimensions of infrastructure (0.44), management (0.41) and environment (0.04) have the greatest impact on increasing sport participation, respectively; also, the environmental dimension with the coefficients of $0.11,0.85,0.04$, and 2.57 has an effect on management, infrastructure, and sport participation development dimension, respectively. Given that most of the components affecting the sport participation development in the present study are related to the sport structure of military Hygiene and cure branch staff and environmental factors that shape behavior more than individual factors that shape behavior affect the sport participation and sport structure of the military Hygiene and cure branch staff; Therefore, the structural factors of sport in the field of military Hygiene and cure branch staff (infrastructure and management) have a more prominent role in the development of sport participation of staff; The importance of having the necessary infrastructure is clear in sport development and based on these results, the type of intervention and the effectiveness of the infrastructure beyond the type of management, environmental effects and individual tendencies increase the sport participation and the sport development among the military Hygiene and cure branch staff. It can also be said that sport facilities and services have motivational aspects. The necessary infrastructure for the development of sport can be in the field of required technologies and 
facilities and equipment of various sports which is usually without them it is very difficult to do sport and develop them. In most explaining of the mentioned relationships, it should be said that different people have a different understanding but visual of sport facilities and services, conversely, environmental perception and its interventions are usually performed in the form of hidden processes. Furthermore, due to the fact that the environment is the field of other levels of variables, it has a significant effect on all variables. In general, environment is a container of activities in which all sport processes take place in it and it affects the behavior of people's sport participation during activities. In conclusion, it should be noted that the sport development among the military Hygiene and cure branch staff requires the creation of infrastructure as well as appropriate structures.

\section{Conclusion}

Finally, it can be said that this research has achieved its intended goals and it has been able to identify important factors influencing the sport development of Military Hygiene and Cure Branch Staff and draw the appropriate model; The results of this study can be used to make more progress in the sport of the Military staff and especially the Hygiene and cure Branch Staff and ultimately increase the mood and Hygiene of these people.

\section{Limitations And Future Research}

The research was limited to the lack of access to some of the most important people in the Military sport, the lack of cooperation from some organizations, and the lack of completion of the questionnaire by individuals; Another limitation of the research was the lack of separation and comparison of the opinions in statistical community and the lack of separation of sport development according to different institutions of the Iranian Military. Also, for future research, it is possible to compare the opinions of the statistical community so that better results can be obtained in the field of this research and similar research can be done in other branches of the Iranian Military.

\section{Declarations}

\section{Ethical Approval and Consent to participate}

This study get the ethical approval from the Baqiyatallah University Ethics Committee with code IR.BMSU.REC.1398.033, and all participants provided the oral consent.

\section{Consent for publication}

All authors express their consent to the publication of this article.

\section{Availability of supporting data}


We agree that the materials described in the manuscript, including all relevant raw data, will be freely available to any scientist wishing to use them for non-commercial purposes, without breaching participant confidentiality.

\section{Competing interests}

Not applicable

\section{Funding}

Not applicable

\section{Authors' contributions}

Mr. Shirvani and Mr. Bahadori were involved in presenting the original plan and implementing the plan and Mr. Darvishi was involved in collecting data, analyzing and interpreting and writing the article; all authors contributed to the initial writing and revision of the article.

\section{Acknowledgements}

This article is the result of the findings of the research project of the Center for Sport Physiology in Baqiyatallah University of Medical Sciences. Researchers need to appreciate the support and advice of the University's Sport Physiology Center.

\section{References}

1. Boon C, Eckardt R, Lepak DP \& Boselie P. Integrating strategic human capital and strategic human resource management. The International Journal of Human Resource Management. 2018;29(1), 3467.https://doi.org/10.1080/09585192.2017.1380063

2. Eze I \& Omena ES. (2019). the Importance of Human Resource in Nigerian Organisational Development. The Melting Pot, 5(2), 65-72.

3. Sotiriadou P. Sport development planning: The Sunny Golf Club. Sport Management Review. 2013; 16(4), 514-523. https://doi.org/10.1016/j.smr.2012.09.002

4. Nikkhoo M, Mohammadi N, Barari AR. Relationship indoor school sports Olympiad with achieve the objectives of fundamental transformation document Ministry of Education. International Journal of Sport Studies. 2015; 5(7), 890-894.

5. Sun F, Norman IJ, \& While, A. E. Physical activity in older people: a systematic review. BMC public Hygiene. 2013;13(1), 449. https://doi.org/10.1186/1471-2458-13-449

6. Puetz TW, O'Connor PJ \& Dishman RK. Effects of chronic exercise on feelings of energy and fatigue: a quantitative synthesis. Psychological bulletin. 2006;132(6), 866-876. DOI: 10.1037/00332909.132.6.866 
7. Sonnentag S, \& Jelden S. Job stressors and the pursuit of sport activities: a day-level perspective. Journal of occupational Hygiene psychology. 2009;14(2), 165-181. https://doi.org/10.1037/a0014953

8. Kartakoullis N, Karlis G \& Karadakis M. (2009). Sports for All Philosophy: The evolution in Cyprus and the Transfer from a Sport to a Hygiene Orientationm. International Journal of Sport Management, Recreation \& Tourism. 2009; 3, 47-60. DOI: 10.5199/ijsmart-1791-874X-3d

9. Ajadi M, Olaoye A Alabidun M. Factors militating sports development among nigerian army force in Sobi Barrack Ilorin, Kwara State. KIU Journal of Social Sciences. 2017; 3(2), 343-350.

10. Green M \& Collins S. Policy, politics and path dependency: Sport development in Australia and Finland. Sport management review. 2008;11(3), 225-251. https://doi.org/10.1016/S14413523(08)70111-6

11. Edwards MB. (2015). the role of sport in community capacity building: An examination of sport for development research and practice. Sport management review. 2015; 18(1), 6-19. https://doi.org/10.1016/j.smr.2013.08.008

12. Brown R \& Brown I. (2005). The application of quality of life. Journal of Intellectual Disability Research. 2005; 49(10), 718-727. https://doi.org/10.1111/j.1365-2788.2005.00740.x

13. Sotiriadou K, Shilbury D, \& Quick S. The attraction, retention/transition, and nurturing process of sport development: Some Australian evidence. Journal of sport management. 2008; 22(3), 247-272. https://doi.org/10.1123/jsm.22.3.247

14. Mohammadi Kh, Ahmadi Kh, Fathi Ashtiani A, Azad Fallah P, Ebadi A. Determining the Psychological Hygiene Indicators of the Military. Journal of Military Medicine. 2014; 3(4), 239-248.

15. Adams RA, Higgins T, Potter S \& Evans SA. The effect of physical activity on hematological predictors of cardiovascular risk-evidence of a dose response. Clinical hemorheology and microcirculation. 2012; 52(1), 57-65. DOI: 10.3233/CH-2012-1566

16. Blair SN, Cheng Y \& Holder JS. (2001). is physical activity or physical fitness more important in defining Hygiene benefits? Medicine \& Science in Sports \& Exercise, 33(6), S379-S399.

17. Tomczak A. Physical activity of soldiers in the Polish Military's military administration units and special units. Biomedical Human Kinetics. 2012; 4(1), 93-97. DOI: 10.2478/v10101-012-0017-x

18. Saadattalab MB, Ghahreman tabrizi k, Nouraie T. Sport Needs in Military Training Centers from the Perspective of Soldiers and Explaining their Attitudes. Military Management Quarterly. 2015; 57, 5981.

19. Pḷavina L. Assessment of the physical activity level for the staff military personnel. Papers on Anthropology. 2011; 20, 351-358. DOl: https://doi.org/10.12697/poa.2011.20.32

20. Gerber M, Kellmann M, Hartmann T \& Pühse U. Do exercise and fitness buffer against stress among Swiss police and emergency response service officers? Psychology of Sport and Exercise. 2010; 11(4), 286-294. https://doi.org/10.1016/j.psychsport.2010.02.004

21. Tengpongsthorn W. Factors affecting the effectiveness of police performance in Metropolitan Police Bureau. Kasetsart Journal of Social Sciences. 2017; 38(1), 39-44. 
https://doi.org/10.1016/j.kjss.2016.07.001

22. Rowe K, Shilbury D, Ferkins L, \& Hinckson E. Sport development and physical activity promotion: An integrated model to enhance collaboration and understanding. Sport management review. 2013; 16(3), 364-377. http://dx.doi.org/10.1016/j.smr.2012.12.003

23. Gill DL \& Deeter TE. Development of the sport orientation questionnaire. Research Quarterly for Exercise and Sport. 1988; 59(3), 191-202.https://doi.org/10.1080/02701367.1988.10605504

24. Hu LH Cheng CF \& Wu JZ. Professional Volleyball Development in Taiwan's Sports Industry. International Journal of Computational Intelligence Systems. 2018; 11, 1082-1090. https://doi.org/10.2991/ijcis.11.1.82

25. Krsmanović S, Branković M \& Radšoević I. Human resources: Main factor in the development of sports. Activities in Physical Education \& Sport. 2014; 4(1), 84-86.

26. Wang X. Research of Development Strategy of Mass Sports in China under Goal of Overall Construction of Well-being Society. Paper presented at the 2013 International Conference on the Modern Development of Humanities and Social Science. 2013; Pp: 457-459.

https://doi.org/10.2991/mdhss-13.2013.121

27. De Bosscher V, De Knop P, Van Bottenburg M \& Shibli SA conceptual framework for analysing sports policy factors leading to international sporting success. European Sport Management Quarterly. 2006;6(2), 185-215.

28. Zarei B, Khodamoradpoor M, \& Rezaei S. Designing the student's sports development strategy in kermanshah university. European Journal of Physical Education and Sport Science. 2017; 3(6), 7284. https://zenodo.org/record/801179

29. Wang D-B, \& Lu W.-J. The Construction and Application of Functional Indexes of Colleges and Universities in the Development of Sports Industry-Analysis Based on Fuzzy Comprehensive Evaluation Method. Eurasia Journal Of Mathematics Science And Technology Education. 2017; 13(8), 6027-6036. DOI: 10.12973/eurasia.2017.01050a

\section{Figures}




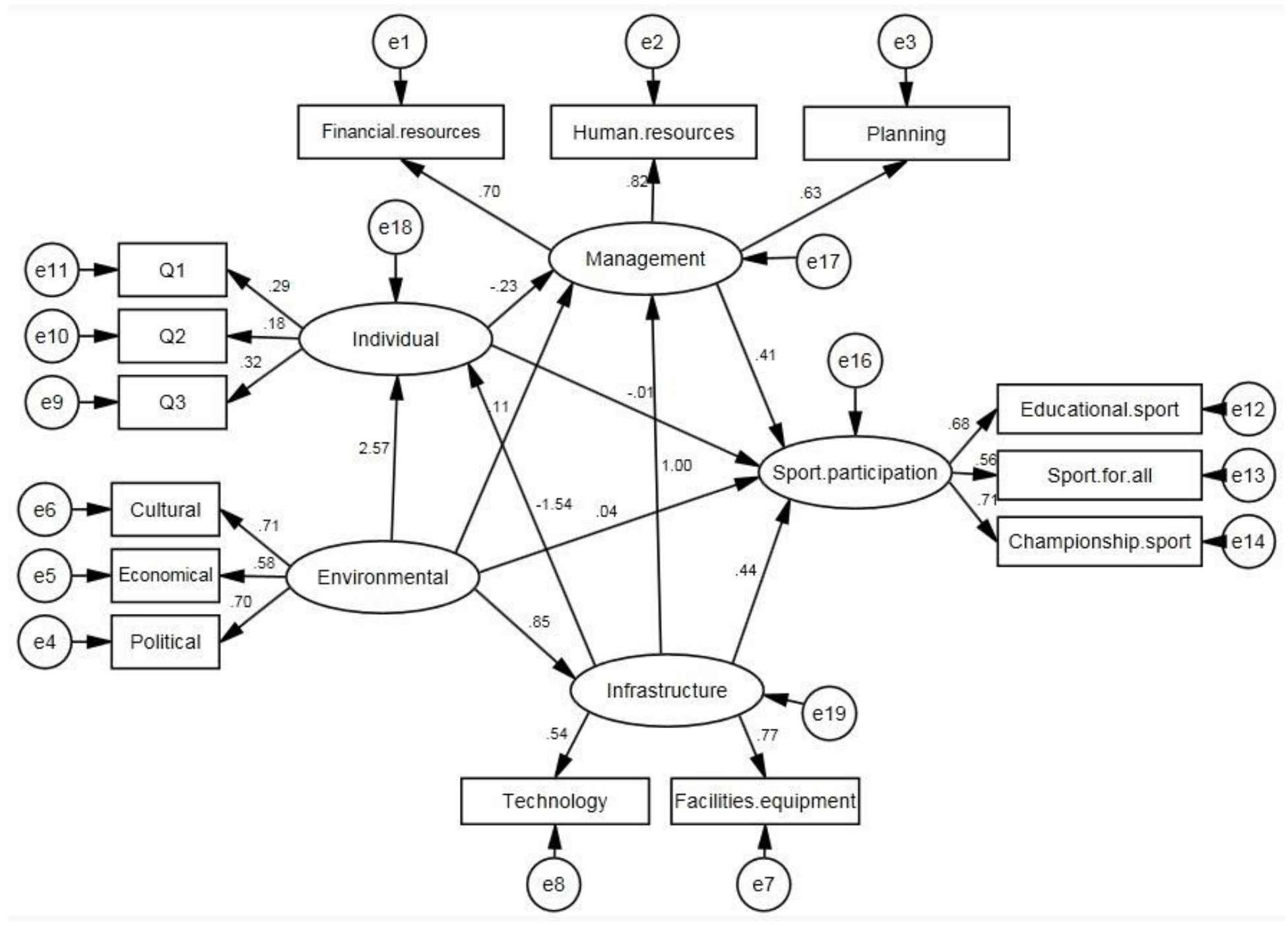

Figure 1

Structural Equation Model of Sport development the Military Hygiene and Cure Branch Staff Note: This figure demonstrate the relationship and effectiveness between the dimensions of the research. 